\title{
Stress and strain monitoring at Tottenham Court Road Station, London, UK
}

Jessica Yu MSc, PhD, DIC, MICE

PhD Researcher, Department of Civil and Environmental Engineering, Imperial College London, London, UK and Geotechnical Engineer, Crossrail Ltd, London, UK

Jamie Standing MSC, PhD, DIC, MICE

Senior Lecturer, Department of Civil and Environmental Engineering, Imperial College London, London, UK
Robert Vollum MSc, PhD, DIC, CEng, MIStructE Reader in Concrete Structures, Department of Civil and Environmental Engineering, Imperial College London, London, UK

David Potts PhD, DSC, FREng, CEng, FICE, FCGI

Professor, Department of Civil and Environmental Engineering, Imperial College London, London, UK

John Burland CBE, DSC(Eng), FREng, FRS

Emeritus Professor, Department of Civil and Environmental Engineering, Imperial College London, London, UK

Removal of old tunnel lining segments at Tottenham Court Road underground railway station in London, UK provided an opportunity to trial in-tunnel instrumentation. Mechanical and electrical resistance strain gauges were installed on adjacent tunnel segments to make discrete measurements of changes in strain owing to unloading as the segments were removed from the tunnel rings. Linear variable differential transformer type displacement transducers were installed. This paper describes the installation process and highlights the lessons learnt for future applications. The in situ strain measurements are presented and compared with the expected response based on laboratory tests conducted on grey cast-iron tunnel segments in the 1970s. The changes in strain measured by both types of strain gauges agreed well with the estimated changes assuming full overburden unloading.

\section{Introduction}

The redevelopment of Tottenham Court Road Underground Station started in 2011 as part of the Tube Upgrade Plan to improve and increase the capacity of the existing facility. The plan is to upgrade the station by 2016 to meet an estimated demand of more than 200000 journeys per day once Crossrail is built.

During April to November 2011, major structural work was carried out on the Northern Line platform tunnels as part of the station upgrade. This included removing tunnel lining segments on the platform side to allow construction of new cross-passages to improve access to the platforms. The works presented an opportunity for the Imperial College research team to trial their field instrumentation.

The main aims of the exercise were

- to make discrete measurements of the strains in selected platform-side segments before and after the segments are removed from the ring

- to make continuous measurements of the opening and closing of circumferential and longitudinal joints on trackside segments which are left in situ and affected by adjacent excavations and tunnel segment removal.

\section{Terminology}

Figure 1 shows the terms relating to tunnel lining that are adopted in this report. Circumferential strain and longitudinal strains are defined as shown in Figure 2. Positive bending refers to the mode of bending having a straightening effect on the segment, and negative bending increases the curvature of the segment.

\section{The instrumentation}

\subsection{DEMEC gauge}

The DEMEC gauge is a portable device which gives measurements of relative movement over a short gauge length. The studs were affixed to the surface of the structure using composite mortar. Once the studs were fixed and the mortar was set, the two points of the DEMEC gauge were carefully placed into the studs to take a zero reading. Further readings were taken subsequently to give the relative movement.

The selected gauge length was $150 \mathrm{~mm}$. The gauge used was a digital gauge with a resolution of $0.001 \mathrm{~mm}$. The accuracy under field conditions was given to be \pm 25 to $50 \mu \varepsilon$, compared to an accuracy of $\pm 5 \mu \varepsilon$ under ideal laboratory conditions (Dunnicliff, 1988).

\subsection{Electrical resistance strain gauges}

A number of $350 \Omega$ rosette-type electrical resistance strain gauges with leadwires attached (Figure 3) were bonded directly onto the prepared cast iron surface using cyanoacrylate. Each strain gauge rosette was $16.5 \mathrm{~mm}$ by $20.3 \mathrm{~mm}$ in plan and less than $1 \mathrm{~mm}$ thick. After the strain gauges were installed, an initial 


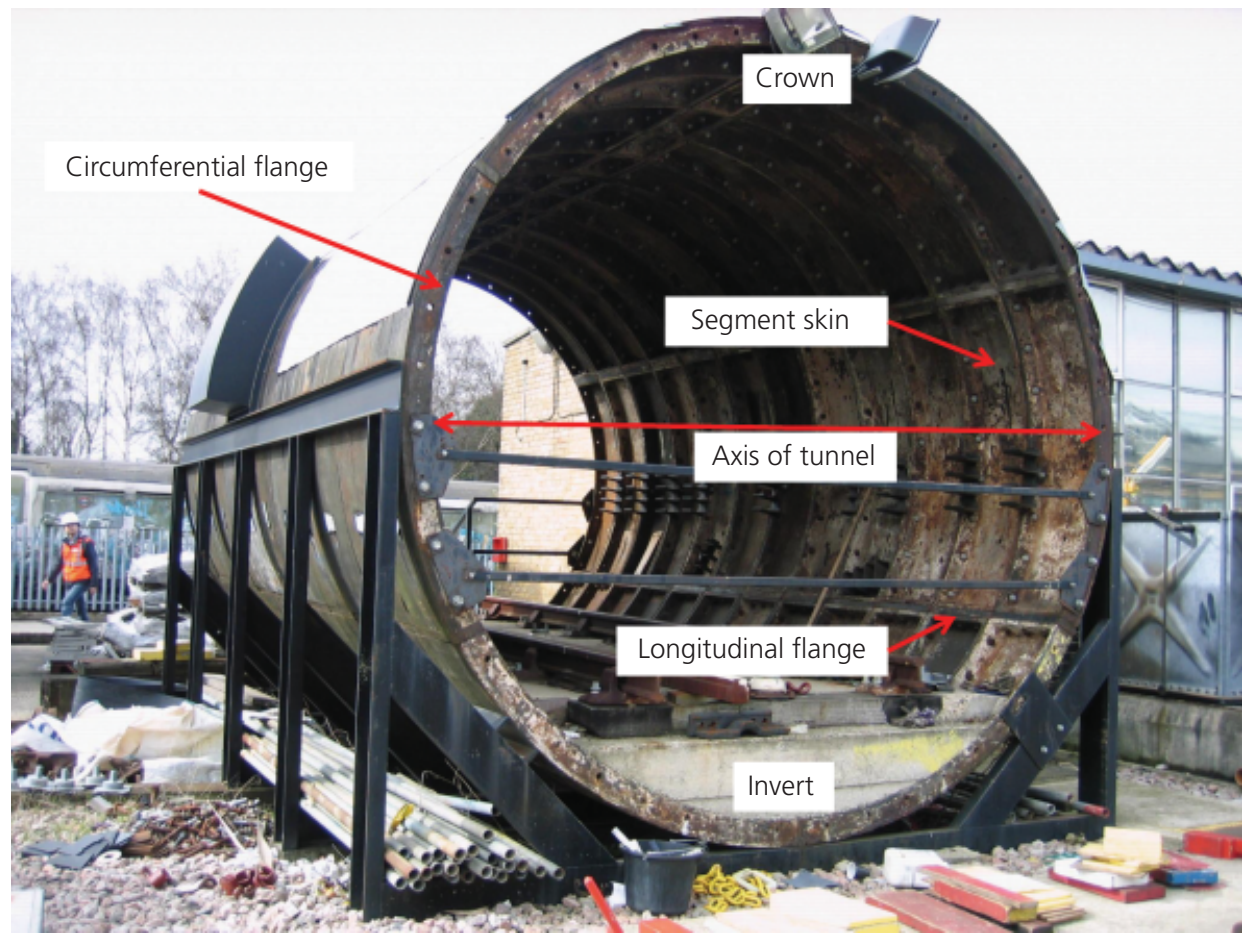

Figure 1. Terms relating to tunnel lining
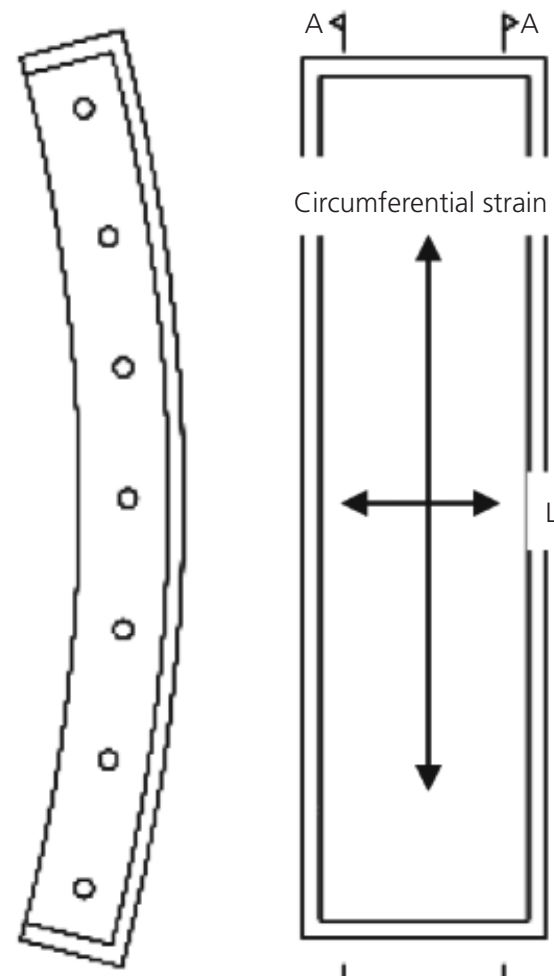

Circumferential strain

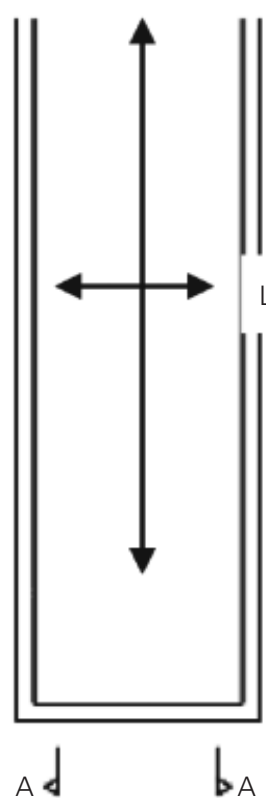

Longitudinal strain

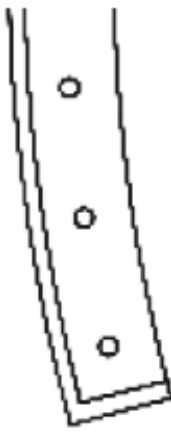

Figure 2. Directions of circumferential and longitudinal strains

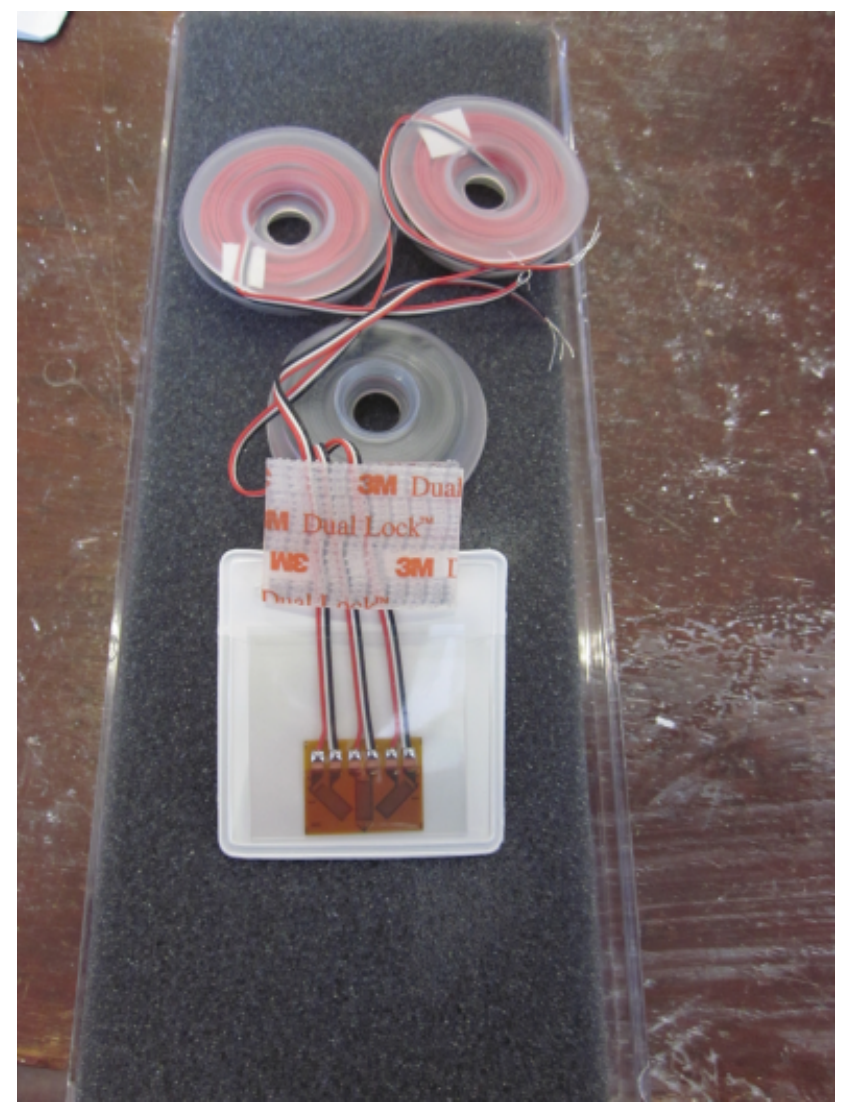

Figure 3. Rosette-type electrical resistance strain gauge 
reading was taken with a portable, battery-powered datalogger, the P3 strain indicator.

A quarter-bridge network with three wires was used in strain monitoring. This, along with the higher resistance $350 \Omega$ resistance gauges, was selected to reduce lead wire effects. The strains caused by temperature change at the gauge were corrected during data processing. An AC excitation voltage was used for the portable strain indicator. Temperature on the surface of the cast iron segments was measured with a laser thermometer probe to facilitate adjustment of strain gauge measurements.

\subsection{Displacement transducers}

Linear variable differential transformer (LVDT)-type displacement transducers were used to measure movement across the circumferential and longitudinal joints of trackside segments. The displacement transducers were fixed onto the segments using a brass holder (Figure 4) which was initially positioned using magnets and then fixed in place using composite mortar.

The measurements were taken using mini-dataloggers. The minidataloggers were housed in a $120 \mathrm{~mm} \times 120 \mathrm{~mm} \times 90 \mathrm{~mm}$ ABS plastic box (Figure 5), which was fixed onto the skin of the trackside segments using composite mortar. There were two boxes in total, one box for two transducers set to $\log$ at 3 min intervals

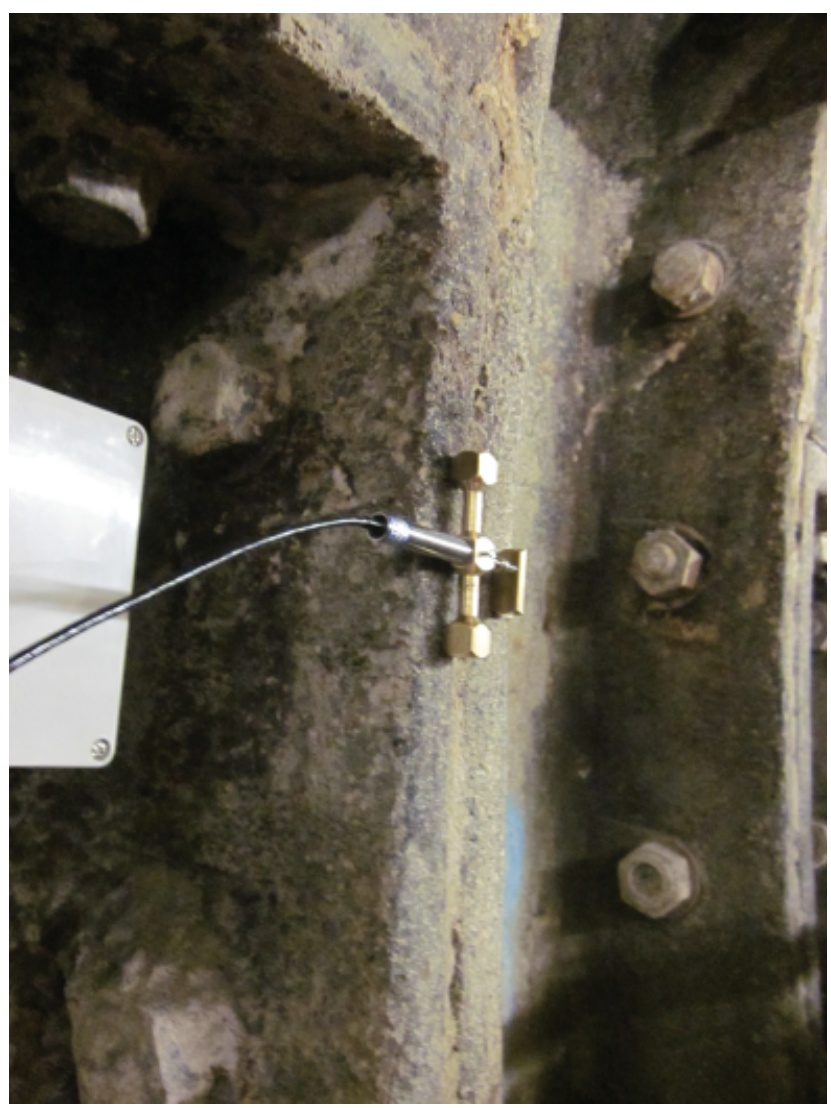

Figure 4. LVDT displacement transducer in brass holder

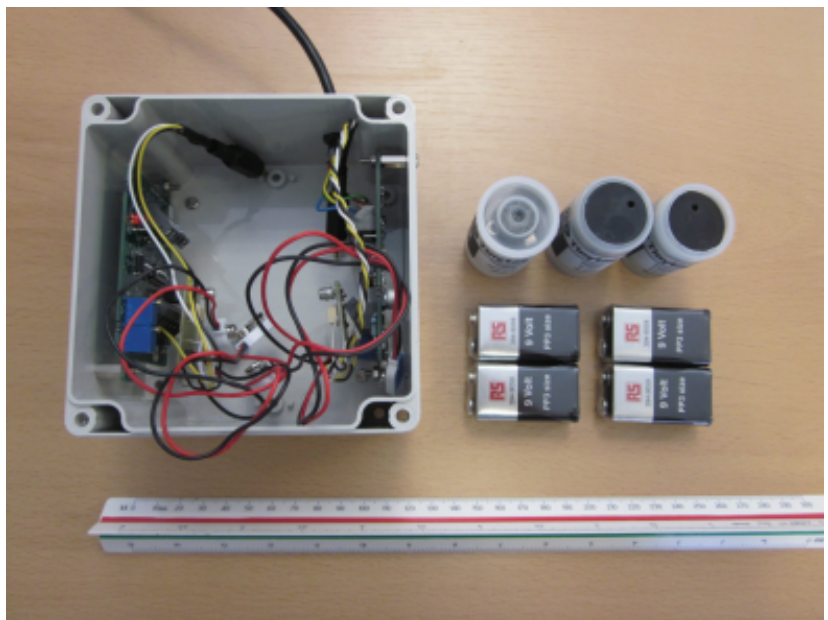

Figure 5. Dataloggers for LVDT and temperature gauge housed in a plastic box

and the other box for two transducers set to $\log$ at $10 \mathrm{~min}$ intervals.

\subsection{Temperature gauge}

There was one temperature gauge with its own datalogger located in each plastic box (Figure 5).

\section{The installation}

\subsection{Platform-side installations}

Mechanical and electrical resistance strain gauges were installed at and just above axis level on segments of one ring on the northbound Northern Line platform tunnel. The positions of the two segments and the approximate locations of the strain gauges are shown in Figure 6 and Figure 7, respectively.

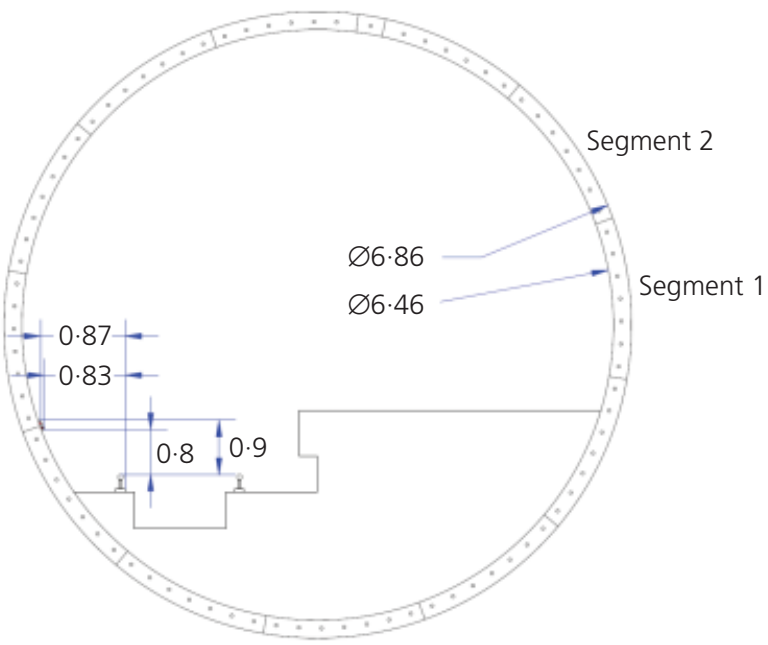

Figure 6. Northern Line northbound platform tunnel looking north 
Stress and strain monitoring at Tottenham

Court Road Station, London, UK

Yu, Standing, Vollum, Potts and Burland

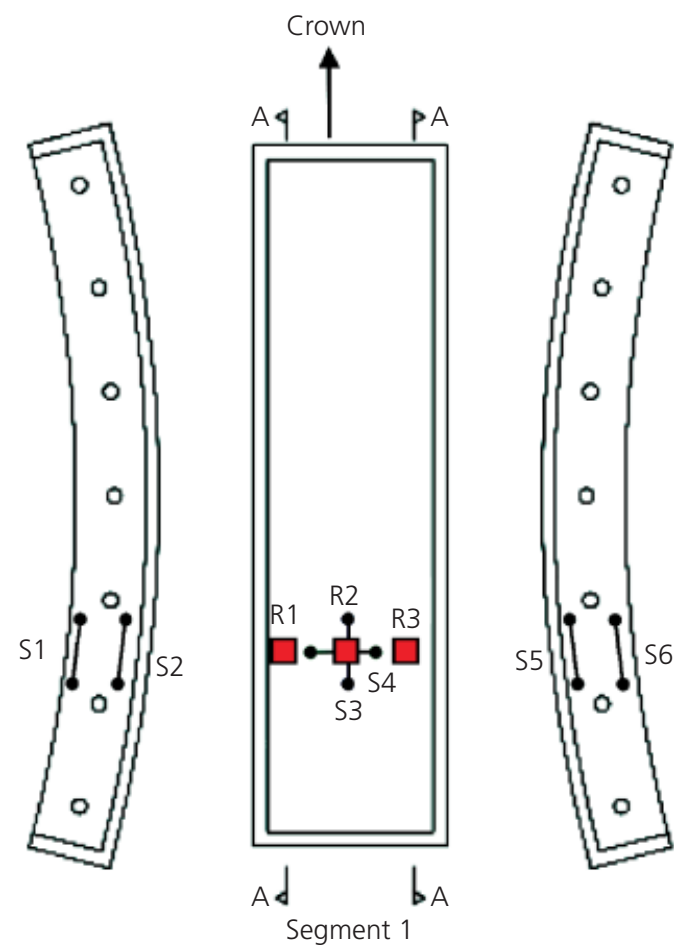

Figure 7. Approximate locations of strain gauges. $(S=D E M E C$ span. $\mathrm{R}=$ strain gauge rosette)

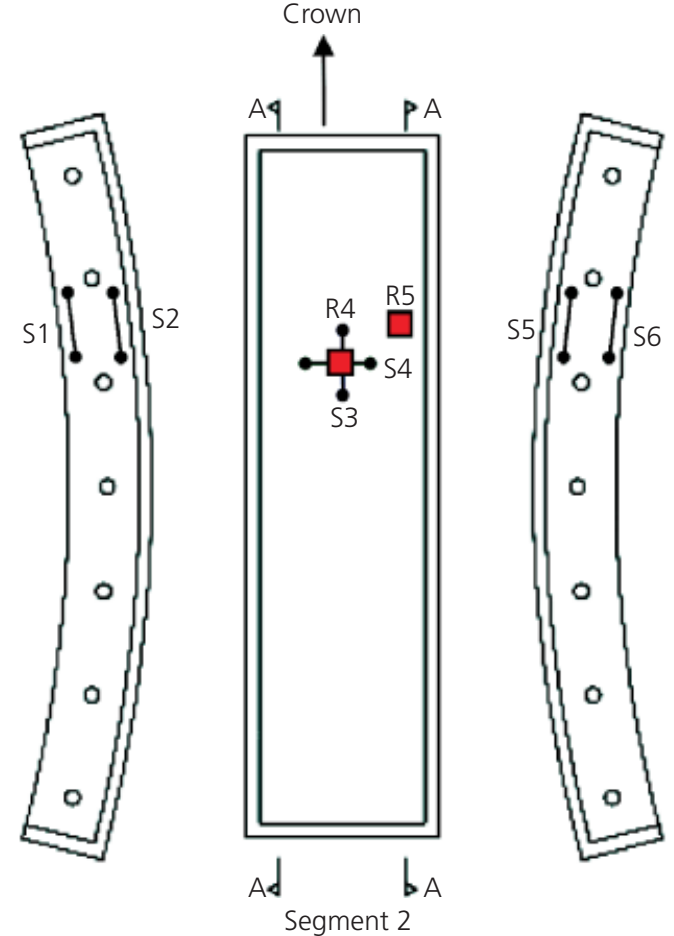

Figure 8 and Figure 9 show the as-built installations. The protective coating seen in the figures consisted of a base layer of Teflon to insulate all bare connections, a layer of butyl rubber sealant, a layer of neoprene rubber and a top layer of aluminium foil tape.

On the inside of the circumferential flange, a pair of DEMEC studs was placed close to the intrados where the maximum strains are expected. Another pair of DEMEC studs was placed close to

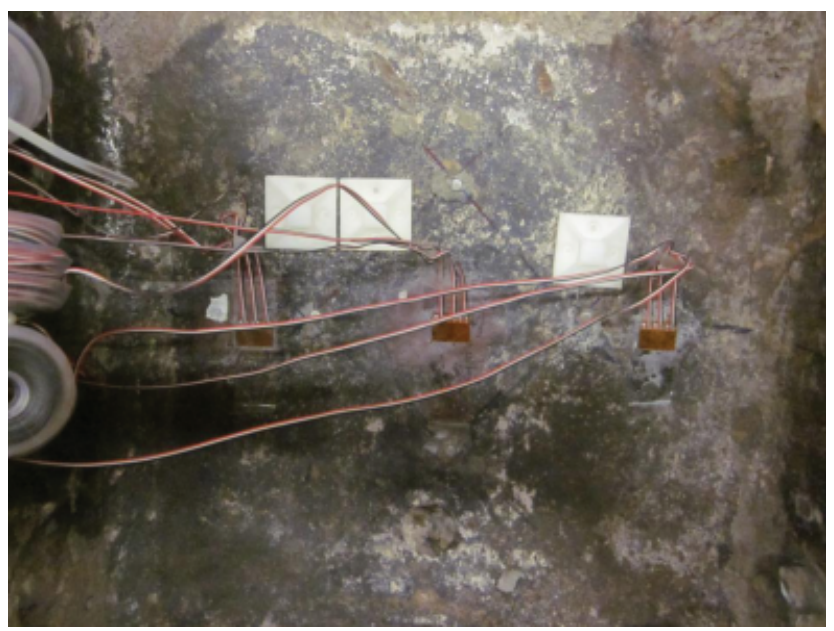

the skin to allow bending strains to be calculated. Two pairs of DEMEC studs were located on the inside of the skin, to measure circumferential and longitudinal strains and allow comparison with the electrical strain gauge rosette.

\subsection{Trackside installations}

Figure 10 shows the location of the two datalogging boxes on the trackside segment. Each box housed three dataloggers, one for a temperature gauge and two for the LVDTs. One LVDT from each

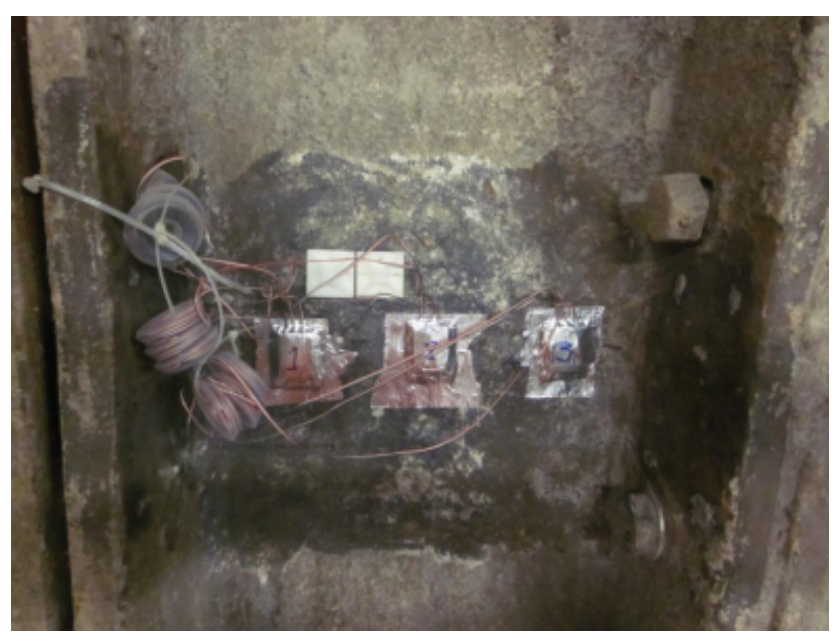

Figure 8. Strain gauges on segment 1 . Without protective coating (left) and with protective coating (right) 


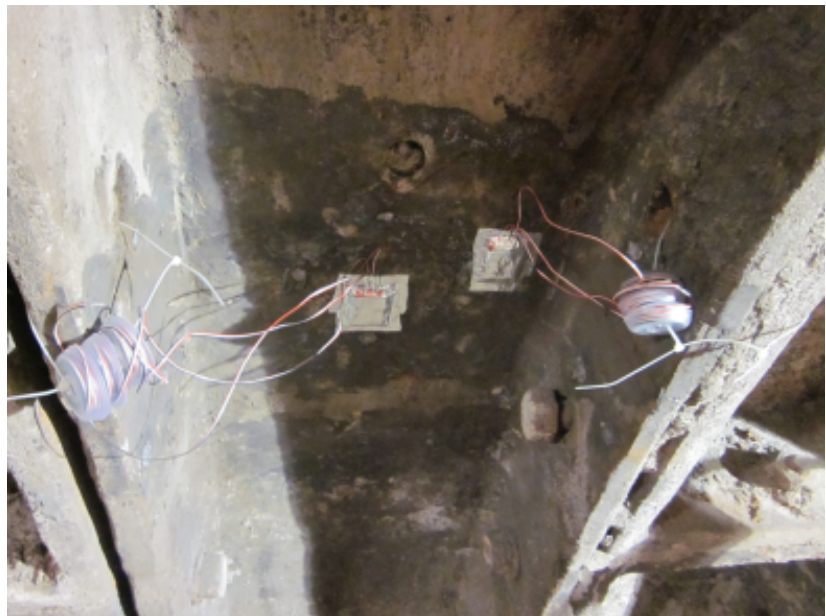

Figure 9. Strain gauges on segment 2

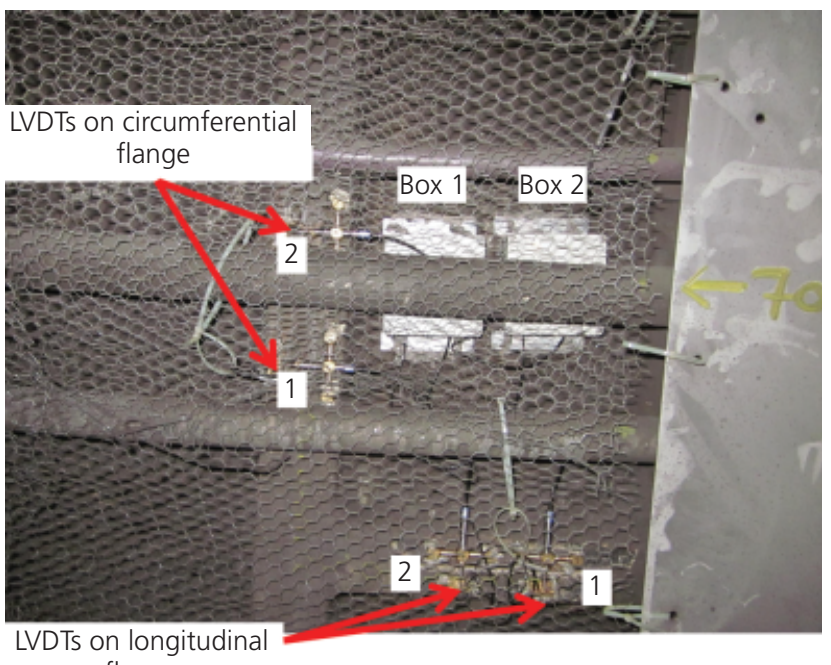

flange

Figure 10. As-built photo showing locations of LVDTs and boxes housing loggers

box was placed across the longitudinal joint and the other LVDT was placed across the circumferential joint.

The loggers in box 1 were set to log every $3 \mathrm{~min}$ and the loggers in box 2 were set to $\log$ every $10 \mathrm{~min}$ (refer to Figure 10).

\section{Estimation of unloading strains}

It was assumed that when the platform tunnel segments were removed from the tunnel lining they were completely unloaded. The circumferential unloading strain assuming the full ground overburden was estimated to provide a comparison with the strains measured using the mechanical and electrical strain gauges.

The ground level was estimated to be at $25.0 \mathrm{~m}$ OD obtained from spot heights shown on drawing 1D0101-G0G00-G00-P01016 Rev B from Geotechnical Sectional Interpretative Report
1\&2: Royal Oak to Liverpool Street, Volume 3: Drawings, Report No. 1D0101-G0G00-00551 (GCG, 2009).

The tunnel axis for the London Underground Ltd (LUL) Northern Line platform tunnel was estimated to be at $-5.0 \mathrm{~m}$ OD from drawing HAG-N105-8742-TUN-D-SEC-5-03426 by Halcrow for the Tottenham Court Road Station Upgrade project. The axis level coincided with the London Clay and Lambeth Group interface (Halcrow, 2008).

Information on the geometry of the lining segments was obtained from LUL Archive Drawing No. 146 for a $21 \mathrm{ft} 2 \frac{1}{2}$ in $(6 \cdot 46 \mathrm{~m})$ internal diameter tunnel. The section properties were calculated and used to estimate the tensile strain in the segment from the release of the hoop stress. The hoop load was estimated assuming $30.0 \mathrm{~m}$ of overburden. The resulting strain was calculated to be about $400 \mu \varepsilon$ when the Young's modulus was taken to be $100 \mathrm{GPa}$ for the grey cast iron.

\section{Previous laboratory tests}

Thomas (1977) investigated the structural behaviour of bolted ordinary grey cast iron (GCI) and spheroidal graphite iron (SGI) tunnel segments in the laboratory. The segments were dimensioned such that six GCI segments plus a key piece would join to form a ring of $3.83 \mathrm{~m}$ ID, whereas 12 SGI segments plus a key piece would join to form a ring of $3.86 \mathrm{~m}$ ID. As GCI behaves hysteretical upon loading and unloading whereas SGI exhibits little hysteresis, Thomas' experiments were mostly performed on the SGI segments.

Thomas (1977) loaded an SGI segment at its quarter points. The loading was applied to the circumferential flanges and not onto the skin. The experimental investigation suggested that positive bending distorts the segment as shown in Figure 11. As the circumferential flanges straighten, the relatively flexible skin dishes radially outwards, which results in a distorted crosssection with the inside skin experiencing longitudinal compressive strain and the outside skin experiencing longitudinal tensile strain.

Thomas (1977) also investigated the effect of ground pressure on the bending characteristics of an SGI segment. A uniform pressure was applied to the back of a single SGI segment (Figure 12). This pressure caused the skin to dish inwards and this dishing inwards of the skin induced longitudinal strains in the skin in the opposite manner to positive bending.

\section{Results from DEMEC measurements}

\subsection{Unloading strains owing to removal of segment from ground}

Using the baseline and post-segment-removal DEMEC measurements on spans 1, 2 and spans 5, 6 on the circumferential flanges (Figure 7), the axial and bending stresses owing to unloading were estimated. In the calculations, the strain was assumed to 

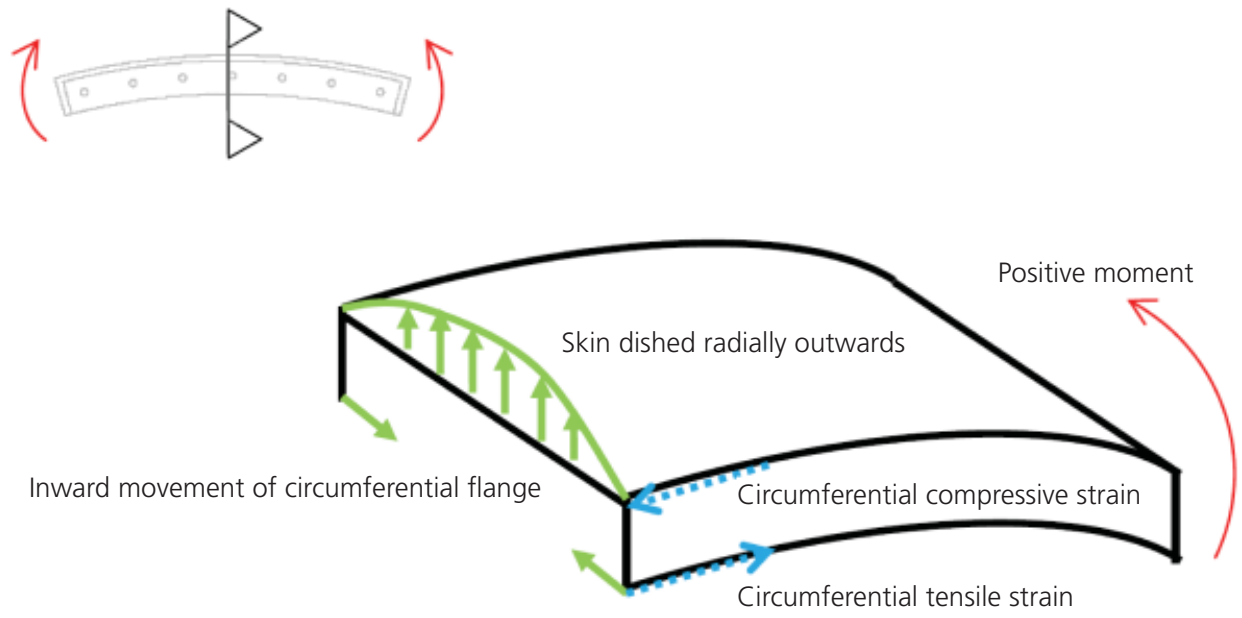

Circumferential tensile strain

Cross-section
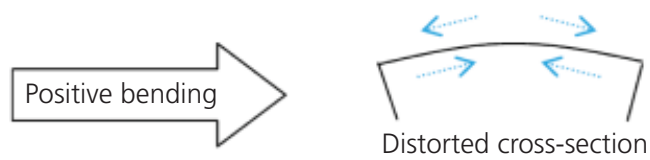

Longitudinal compressive strain inside skin

Longitudinal tensile strain outside skin

Figure 11. Schematic diagram showing distortion associated with positive bending (distortion is exaggerated)

vary linearly between spans 1 and 2 and spans 5 and 6. A constant modulus of $100 \mathrm{GPa}$ was adopted. The results are presented in Figure 13, along with the stress blocks, presented as variation in stress with distance away from the extrados, for each circumferential flange.

The measurements from all four circumferential flanges indicated circumferential tension and a positive bending moment upon unloading, which was expected as the segments would have experienced circumferential compression and negative bending moment (see Figure 14) while underground. It was not clear why the circumferential tension was higher on span 1-2 for both segments. However, the magnitude of circumferential tension from span 1-2 on both segments compared well with that calculated assuming full overburden unloading, which was estimated to be $940 \mathrm{kN}$.

On the inside of the skin, DEMEC span 3 measured tensile circumferential strains from unloading, and DEMEC span 4 measured compressive longitudinal strains, for both segments (Figure 7). Referring to Figure 11, these distortions could be associated with the dishing outwards of the skin related to positive bending. The ratio of the longitudinal strain to circumferential strain was 1.2 for segment 1 and 1.0 for segment 2 . Given that grey cast iron has a Poisson ratio of approximately $0 \cdot 26$, this distortion of the skin was not attributable to the Poisson effect.

\subsection{Intermediate DEMEC measurements}

A wire cage bracket was attached onto the skin to protect strain gauge rosettes from mechanical damage (Figure 15). Owing to the presence of the wire bracket, only DEMEC spans 1 and 6 (see Figure 7) were available for intermediate monitoring between the day of installation and the day of segment removal on 11 August 2011. The results are given in Figure 16.

For segment 1, spans 1 and 6 measured increasing tensile strain, which is in line with the segment experiencing positive moment as the excavation works around the segment releases the ground loading. However, for segment 2, spans 1 and 6 measured increasing compressive strains during the excavations works around the segment, while the segment was still part of the lining ring.

\section{Results from strain gauge rosettes}

\subsection{Unloading strains owing to removal of segment from ground}

Using the baseline and post-removal strain measurements from each strain gauge in a rosette, the principal major and minor direct strains and the orientation of the principal direct strain directions on the surface of the cast iron were calculated for each rosette location. The calculations included corrections for strain gauge thermal output and gauge factor variation with temperature. The temperature corrections were done according to Technical Note TN-504-1, entitled 'Strain gage thermal output and gage factor 


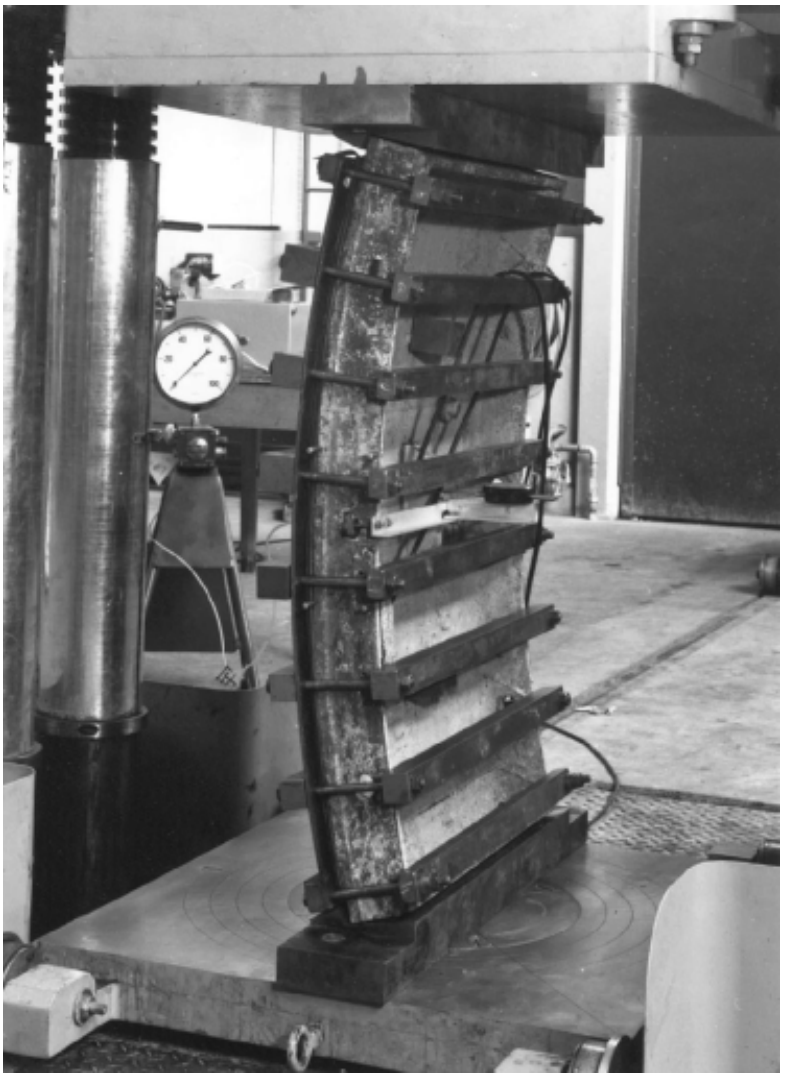

Figure 12. Uniform loading on back of SGI segment (Thomas, 1977) variation with temperature', supplied by the electrical resistance strain gauge manufacturer, Vishay Precision Group (2010).

Refer to Figure 7 for the locations of the rosettes. The results for segment 1 are presented in Figure 17. The results for segment 2 are presented in Figure 18. Each plot shows the direction and magnitude of the major and minor principal direct strains on the surface of the cast iron. The $y$-axis represents the circumferential direction and the $x$-axis represents the longitudinal direction as illustrated in Figure 2.

The strain gauges measured tensile strains in the sub-circumferential direction and compressive strains in the sub-longitudinal direction. This is consistent with measurements from DEMEC spans 3 and 4 . The circumferential strain and longitudinal strain at the locations of rosette 2 and rosette 4 have been resolved from the major and minor principal direct strains to allow comparison with the DEMEC measurements. This is given in Table 1.

From Table 1, it can be seen that there was less than 5\% difference in the circumferential unloading tensile strains measured using the electrical and mechanical strain gauges. However, the difference between the longitudinal strains measured by the two instruments differed greatly, well over $20 \%$. This larger difference corroborates with the positive bending mode of distortion the segment was expected to experience upon unloading: with the skin dishing radially outwards, compressive strain was expected on the inside of the skin in the longitudinal direction. As the DEMEC instrument had a longer gauge length

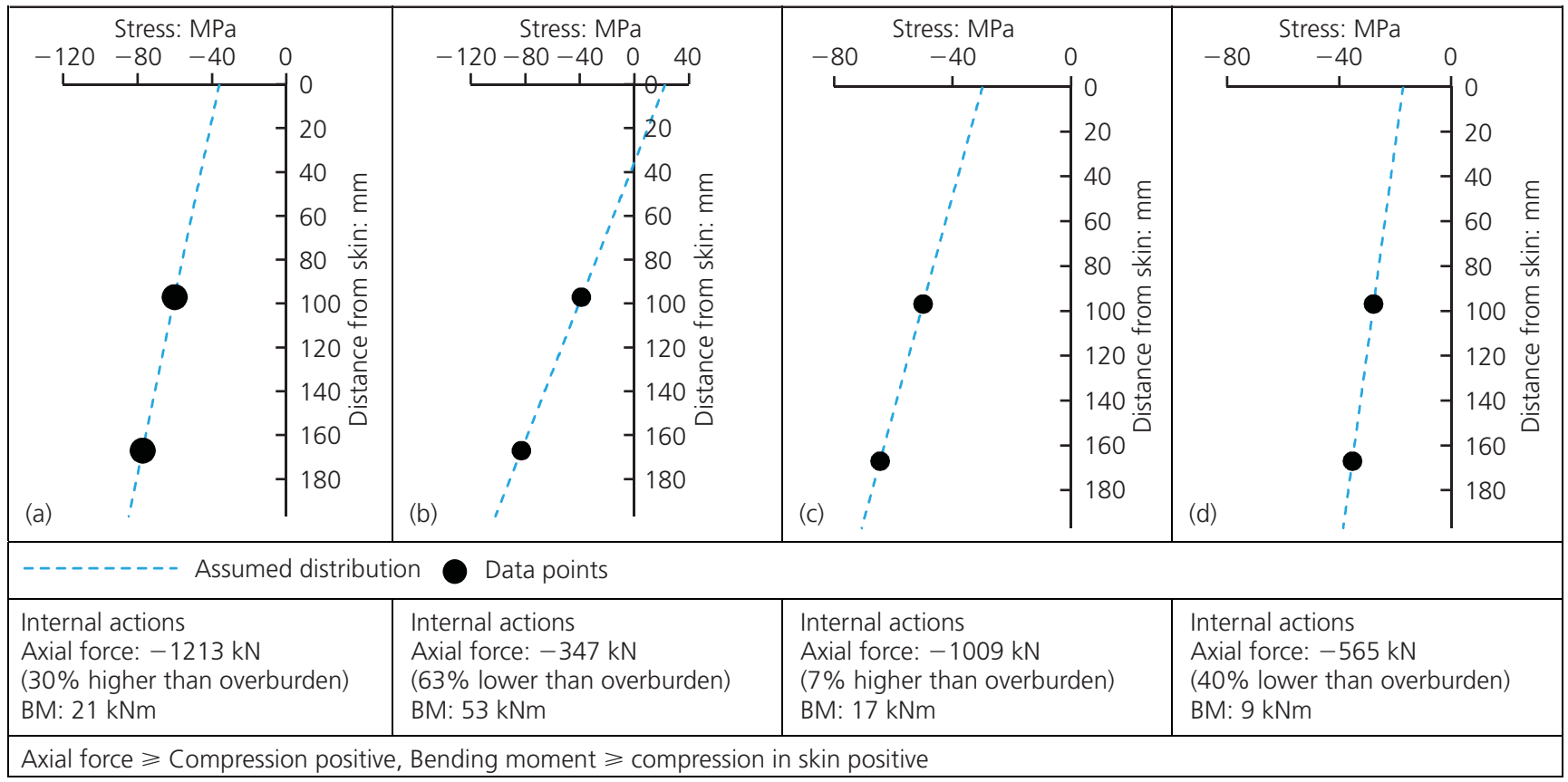

Figure 13. DEMEC results for circumferential flanges:

(a) span $1-2$, segment 1 ; (b) span $5-6$, segment 1 ; (c) span 1-2,

segment 2; (d) span 5-6, segment 2 

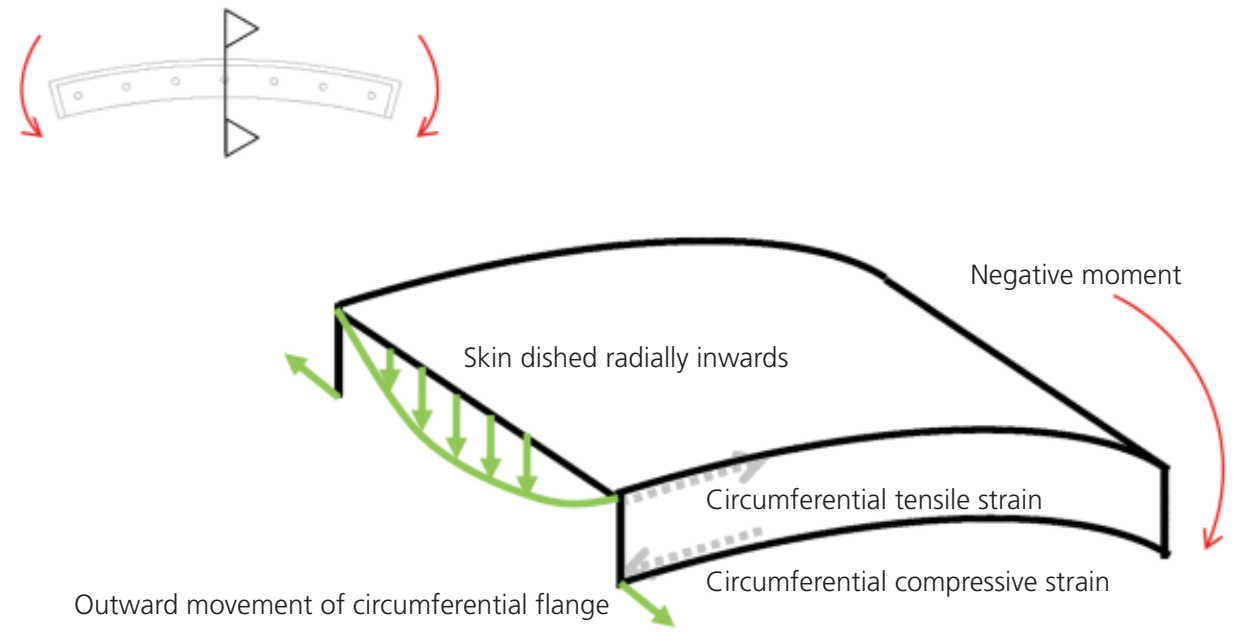

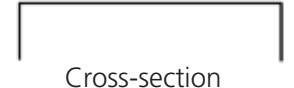

Cross-section

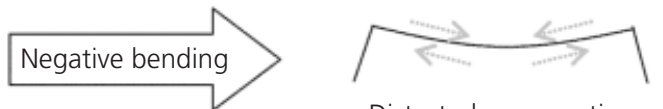

Distorted cross-section

Longitudinal tensile strain inside skin

Longitudinal compressive strain outside skin

Figure 14. Schematic diagram showing distortion associated with negative bending (distortion is exaggerated)

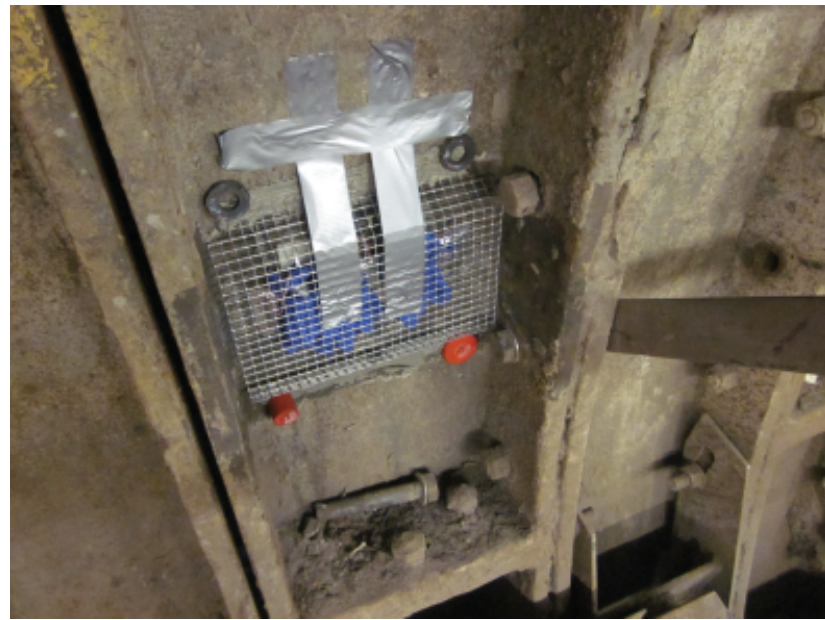

Figure 15. Wire bracket to protect strain gauge rosettes

compared with the rosette, the compressive strain measured by the DEMEC was also larger, because the chord length, rather than the arc length was measured. In the circumferential direction, axial tensile strain dominated over bending strains, and the difference in gauge lengths had smaller effects on the measured strains.

\subsection{Intermediate strain gauge rosette measurements}

The baseline readings and the last set of readings taken before segment removal were used to calculate the changes in principal major and minor strains in the skin. The intermediate DEMEC strains near the intrados of the circumferential flanges suggest that excavation works around the tunnel lining caused positive bending in segment 1 and negative bending in segment 2, before the segments were removed from the tunnel. The results for segment 1 are presented in Figure 19. The results for segment 2 are presented in Figure 20. The plots show the magnitude and direction of the principal major and minor direct strains on the surface of the cast iron. The strains in the circumferential and longitudinal directions have been calculated and are given in the tables.

For segment 1 , the measured strains are predominantly slightly compressive in the longitudinal direction, and slightly tensile in the circumferential direction. The compressive strains in the longitudinal direction are consistent with the assumed mode of positive bending as suggested by the DEMEC readings on the circumferential flange.

For segment 2, the measured strains are tensile in the longitudinal direction, consistent with the negative mode of bending suggested by the DEMEC readings and the associated dishing inwards of the skin. 


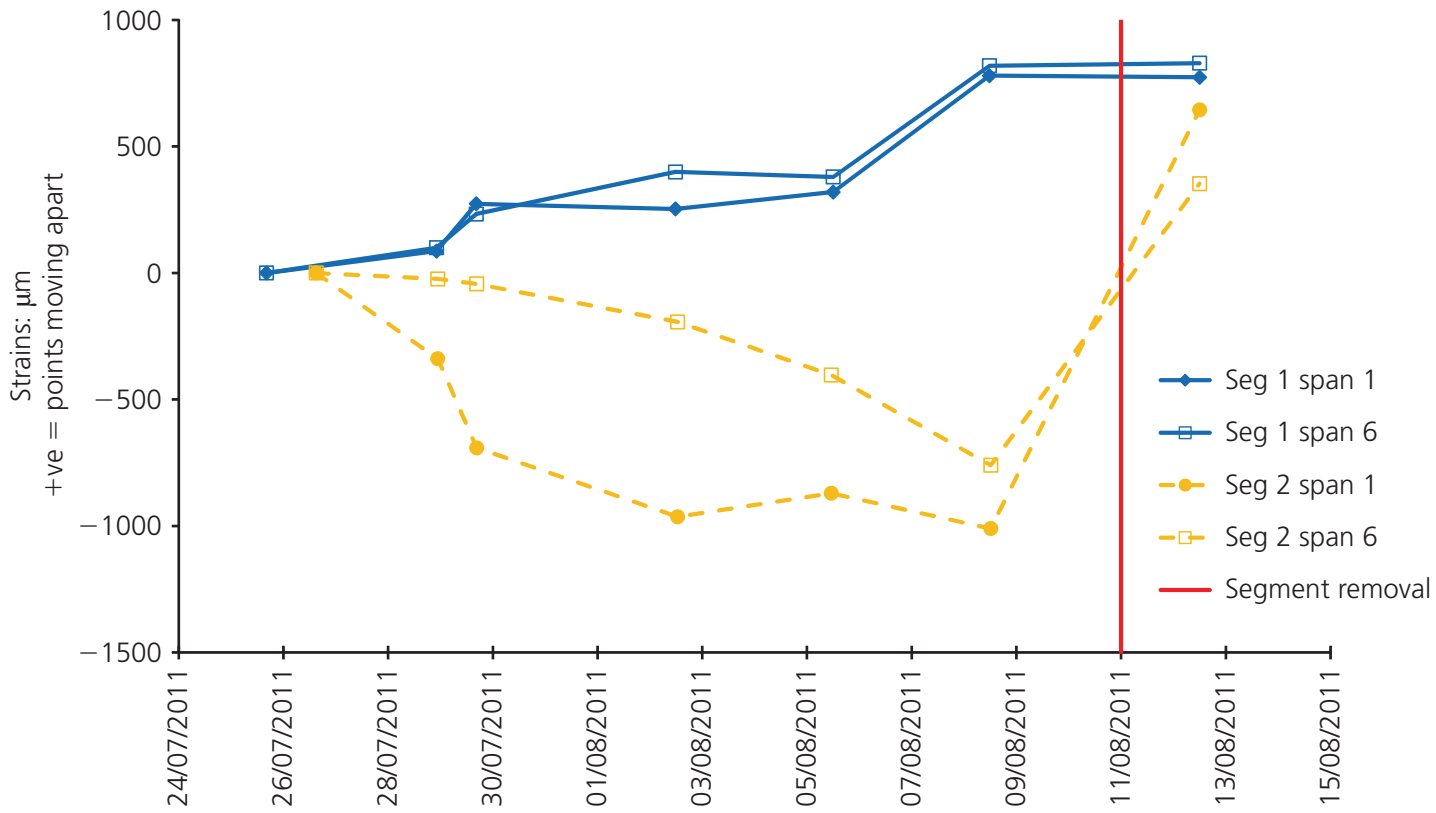

Figure 16. Development of strains on the circumferential flange

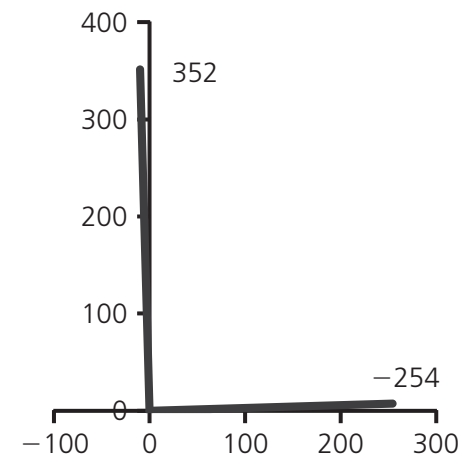

(a)

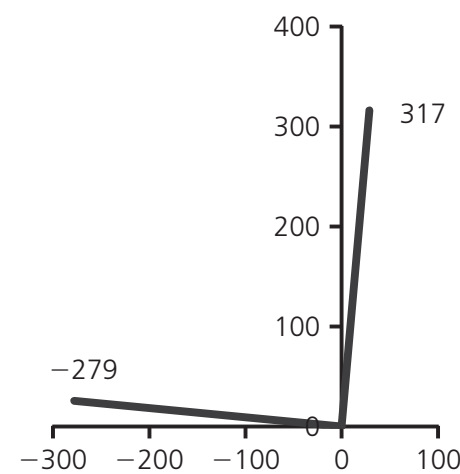

(b)

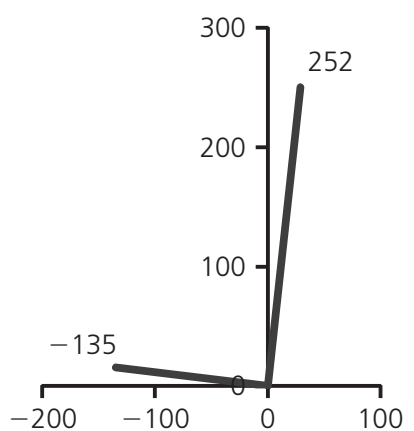

(c)

Vertical axis = circumferential direction; horizontal axis = longitudinal direction; tensile strains positive; unit is microstrain .

Figure 17. Strain gauge results for segment 1: (a) rosette 1;

(b) rosette 2 ; (c) rosette 3

\section{Results from trackside displacement transducers}

Continuous measurements of joint movement were taken by the displacement transducers over a period of 6 weeks. The LVDTs were affected by the diurnal temperature changes in the tunnel. Figure 21 shows the changes in output from the four LVDTs with the diurnal fluctuations smoothed out by using $24 \mathrm{~h}$ running averages. While the estimated displacements were clearly influenced by the overall temperature trends, there was also a downward shift in displacements for three of the four LVDTs. This downward trend was steeper before the platform-side segments were removed (11 August 2011) and flattened out post removal. The LVDTs were calibrated so that an increase in displacement related to the joint opening up.

\section{Conclusion}

The strain release when cast iron segments were removed from a tunnel ring was measured by electrical and mechanical strain gauges. The magnitude of change in strain was similar to that predicted assuming full overburden unloading and a constant modulus of $100 \mathrm{GPa}$. Installation of strain gauges on the circumferential flanges of the segment allowed the computation of change in axial stress and bending moment of the segment owing to unloading. 


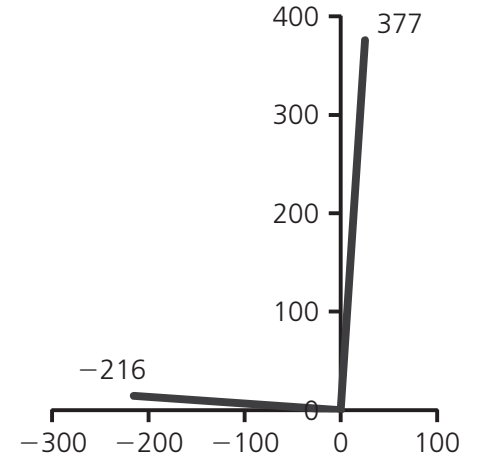

(a)

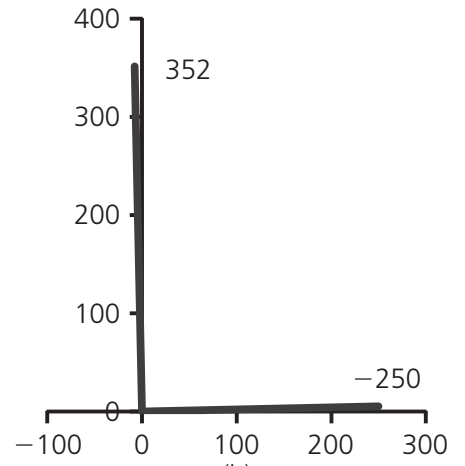

(b)
Vertical axis = circumferential direction; horizontal axis = longitudinal direction; tensile strains positive; unit is microstrain

Figure 18. Strain gauge results for segment 2: (a) rosette 4; (b) rosette 5

\begin{tabular}{llcc}
\hline Segment & & $\begin{array}{c}\text { Circumferential } \\
\text { strain: } \mu \varepsilon\end{array}$ & $\begin{array}{c}\text { Longitudinal } \\
\text { strain: } \mu \varepsilon\end{array}$ \\
\hline 1 & Rosette 2 & 312 & -274 \\
2 & DEMEC & 300 & -353 \\
& Rosette 4 & 374 & -213 \\
& DEMEC & 365 & -370 \\
\hline
\end{tabular}

Tensile strains positive.

Table 1. Comparison of DEMEC and strain gauge rosette results

The use of electrical strain gauge rosettes allowed the principal major and minor direct strains on the surface of the cast iron segment to be estimated, and provided insight into the mode of deformation of the segment.

Measurements made by the LVDT displacement transducers were affected by the diurnal temperature fluctuations in the tunnel.

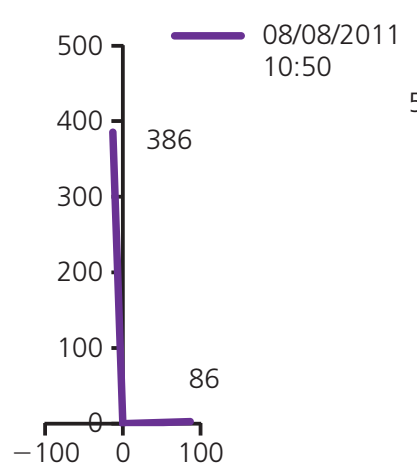

(a)

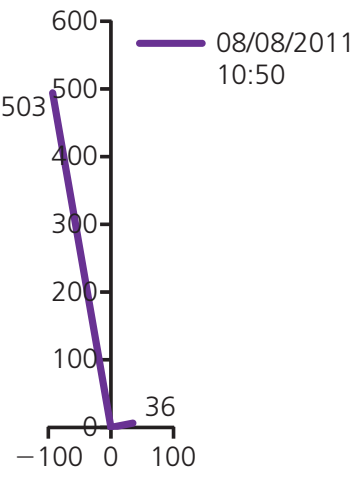

(b)

Vertical axis $=$ circumferential direction;

horizontal axis = longitudinal direction; tensile strains positive.

Figure 20. Intermediate strain gauge results for segment 2 : (a) rosette 4; (b) rosette 5

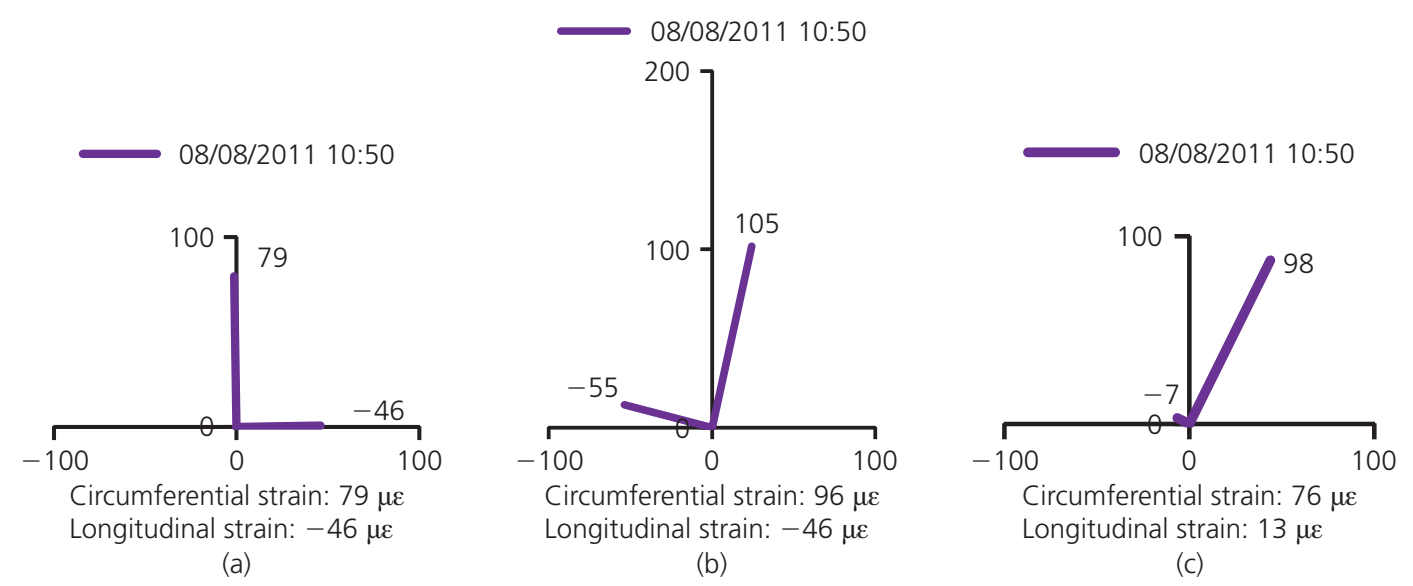

Vertical axis = circumferential direction; horizontal axis = longitudinal direction; tensile strains positive.

Figure 19. Intermediate strain gauge results for segment 1 :

(a) rosette 1 ; (b) rosette 2 ; (c) rosette 3 


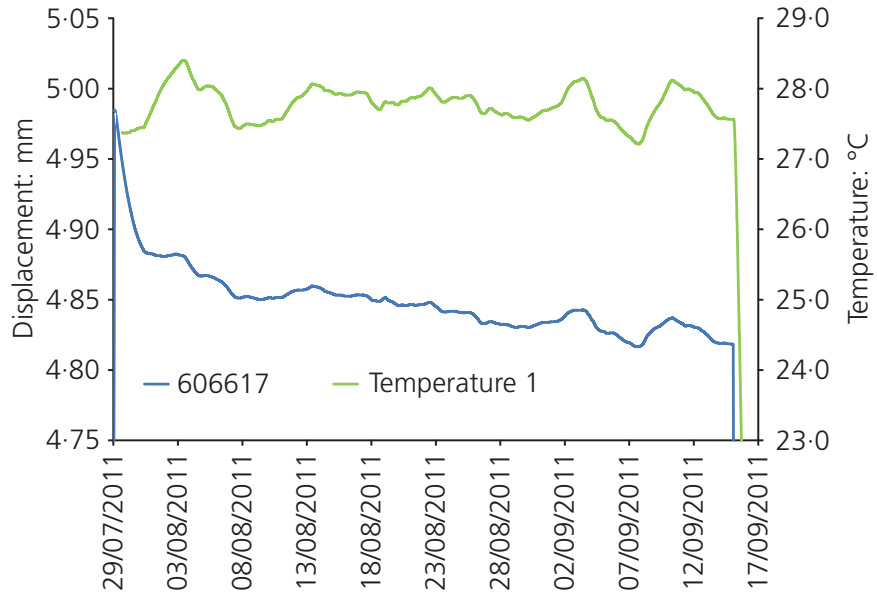

(a)

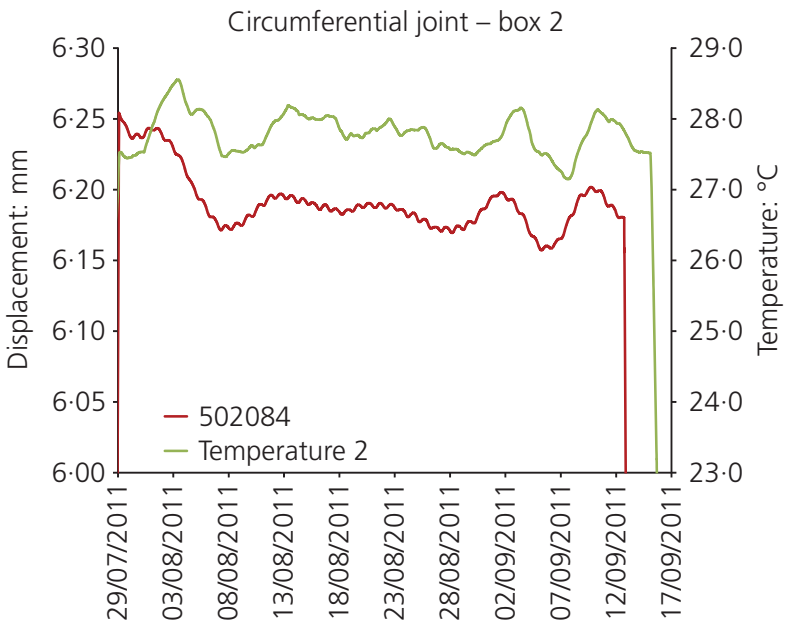

(c)

Figure 21. Comparison of LVDT trends: (a) circumferential joint box 1; (b) horizontal joint - box 1; (c) circumferential joint - box 2; (d) horizontal joint - box 2

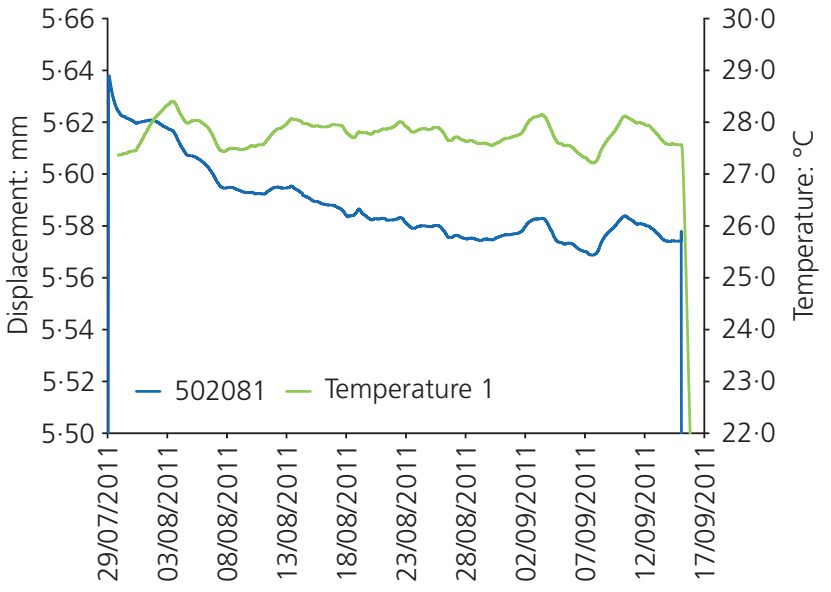

(b)

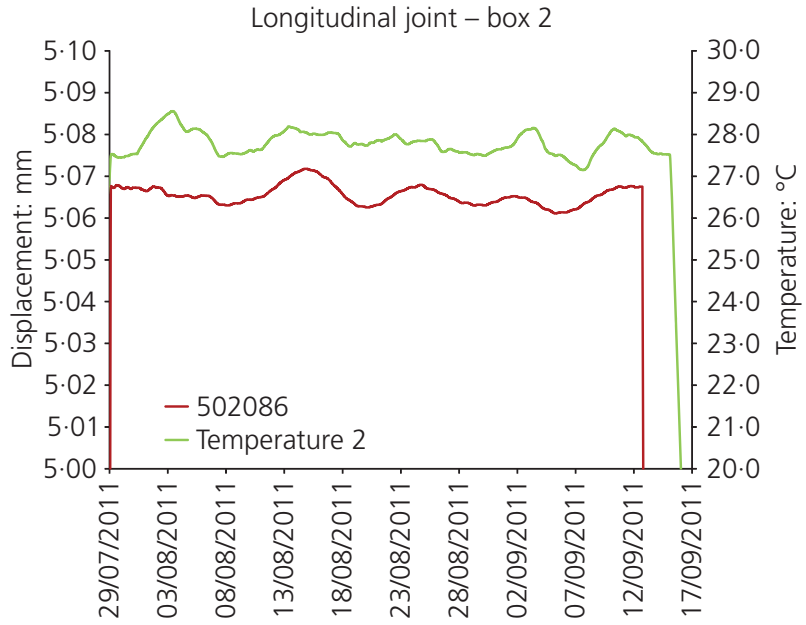

(d)

\section{Acknowledgements}

The authors wish to thank Chris Barnes, Dr Keith Bowers, Neil Moss, Jeremy Pallant and Duncan Parker for all their efforts in making this instrumentation trial possible.

\section{REFERENCES}

Dunnicliff J (1988) Geotechnical Instrumentation for Monitoring Field Performance. Wiley, New York, NY, USA.

GCG (2009) Geotechnical Sectional Interpretative Report 1\&2:

Royal Oak to Liverpool Street. Volume 3: Drawings. Report No. 1D0101-G0G00-00551.

Halcrow (2008) Northern Line Cross Passages/Staircases Long Sections through Staircase No.10, Drawing no. HAG-N1058742-TUN-D-SEC-5-03426 Rev 00. Dated 15/12/2008.

Thomas HSH (1977) Measuring the structural performance of cast iron tunnel linings in the laboratory. Ground Engineering 10(5): 29-36.

Vishay Precision Group (2010) Strain Gage Thermal Output and
Gauge Factor Variation with Temperature. Technical Note $T N-504-1$. Vishay Precision Group. See Report number: 11054. See http: //www.vishaypg.com/docs/11054/tn504.pdf (accessed 28/06/2014).

\section{WHAT DO YOU THINK?}

To discuss this paper, please email up to 500 words to the editor at journals@ice.org.uk. Your contribution will be forwarded to the author(s) for a reply and, if considered appropriate by the editorial panel, will be published as a discussion in a future issue of the journal.

Proceedings journals rely entirely on contributions sent in by civil engineering professionals, academics and students. Papers should be $2000-5000$ words long (briefing papers should be 1000-2000 words long), with adequate illustrations and references. You can submit your paper online via www.icevirtuallibrary.com/content/journals, where you will also find detailed author guidelines. 